\title{
Annealing of $\alpha$-decay damage in zircon: a Raman spectroscopic study
}

\author{
Ming Zhang $\dagger$, Ekhard K H Salje†, Gian Carlo Capitanił, Hugues Leroux \\ Andrew M Clark§, Jochen Schlüter\| and Rodney C Ewing $\mid$ \\ $\dagger$ Department of Earth Sciences, University of Cambridge, Downing Street, \\ Cambridge CB2 3EQ, UK \\ \$ Laboratoire de Structure et Propriétés de l'Etat Solide, Bâtiment C6, \\ Université Sciences et Technologies de Lille, 59655 Villeneuve d'Ascq, France \\ $\S$ Department of Mineralogy, The Natural History Museum, Cromwell Road, London SW7 5BD, \\ UK \\ || Mineralogisches Museum, Mineralogisch-Petrographisches Institut, Universität Hamburg, \\ Grindelallee 48, D-20146 Hamburg, Germany \\ - Department of Nuclear Engineering and Radiological Sciences Department of Geological \\ Sciences, University of Michigan, Ann Arbor, MI 48109-2104, USA \\ E-mail: mz10001@esc.cam.ac.uk (M Zhang)
}

Received 16 December 1999

\begin{abstract}
Recrystallization and structural recovery in $\alpha$-decay damage in zircon samples have been studied using Raman spectroscopy. Fifteen zircon samples with different degrees of radiation damage have been thermally annealed between $600 \mathrm{~K}$ and $1800 \mathrm{~K}$ for up to 28 days and 8 hours. The experimental results from this study reveal that recrystallization in the damaged zircon samples is a multi-stage process that depends on the degree of initial damage of the samples. In partially damaged samples the lattice recovery of damaged crystalline $\mathrm{ZrSiO}_{4}$ takes place at temperatures as low as about $700 \mathrm{~K}$, as shown by a remarkable band-sharpening and a significant increase in the frequencies of $v_{1}$ and $v_{3} \mathrm{Si}-\mathrm{O}$ stretching vibrations together with the external band near $357 \mathrm{~cm}^{-1}$ with increasing temperature. A dramatic increase of Raman scattering intensity of $\mathrm{ZrSiO}_{4}$ occurs in partially damaged samples near $1000 \mathrm{~K}$ due to a recrystallization process involving epitaxial growth. Heavily damaged samples tend to decompose into $\mathrm{ZrO}_{2}$ and $\mathrm{SiO}_{2}$ at high temperatures. Tetragonal $\mathrm{ZrO}_{2}$ has been observed under annealing between $1125 \mathrm{~K}$ and about $1600 \mathrm{~K}$ in heavily damaged samples while monoclinic $\mathrm{ZrO}_{2}$ appears above $1600 \mathrm{~K}$. Weak signals from $\mathrm{ZrSiO}_{4}$ were detected at $1125 \mathrm{~K}$ in highly metamict zircon although the main recrystallization appears to occur near $1500 \mathrm{~K}$ accompanied by a decrease of the volumes of $\mathrm{ZrO}_{2}$ as well as $\mathrm{SiO}_{2}$. This suggests that this recrystallization is associated with the reaction of $\mathrm{ZrO}_{2}$ with $\mathrm{SiO}_{2}$ to form $\mathrm{ZrSiO}_{4}$.

A possible intermediate phase has been observed, for the first time, by Raman spectroscopy in damaged zircons annealed at temperatures between $800 \mathrm{~K}$ and $1400 \mathrm{~K}$. This phase is characterized by strong, broad Raman signals near 670,798 and $1175 \mathrm{~cm}^{-1}$. Prolonged isothermal annealing at $1050 \mathrm{~K}$ results in a decrease of these characteristic bands and eventually the disappearance of this intermediate phase.
\end{abstract}

\section{Introduction}

Zircon $\left(\mathrm{ZrSiO}_{4}\right)$ is widely used in the ceramic, foundry and refractory industries. It has also been proposed as a waste form for the disposal of plutonium from dismantled nuclear weapons (Burakov 1993, Anderson et al 1993, Ewing et al 1995, Weber et al 1996, Ewing 1999). Self-radiation damage from $\alpha$-decay of the incorporated actinides can affect the durability and 
performance of these actinide-bearing phases. The evaluation of the effect of radiation on the crystalline phase and understanding of the damage and recrystallization mechanisms and the structure of the damaged phase are one of the critical concerns for this application.

Zircon is tetragonal $\left(I 4_{1} /\right.$ amd and $\left.Z=4\right)$ (Hazen and Finger 1979). The ideal structure consists of a chain of alternating, edge-sharing $\mathrm{SiO}_{4}$ tetrahedra and $\mathrm{ZrO}_{8}$ triangular dodecahedra extending parallel to the crystallographic $c$-axis. Natural zircons are commonly found with $\mathrm{U}$ and $\mathrm{Th}$, as well as other rare earth elements. Due to radioactive decay of naturally occurring radionuclides and their daughter products in the ${ }^{238} \mathrm{U},{ }^{235} \mathrm{U}$ and ${ }^{232} \mathrm{Th}$ decay series the structure of zircon can become heavily damaged over geological time. As a result, natural zircon is commonly found in the 'metamict' state, an aperiodic or amorphous state caused by $\alpha$-decay radiation damage (Ewing 1994).

Annealing of metamict zircon is typically done in order to restore the original crystal structure for the purpose of phase identification and to gain an understanding of the recrystallization mechanism. Previous investigations (Stott and Hilliard 1946, Vaz and Senftle 1971, Vance and Anderson 1972, Mursic et al 1992a, Weber 1991, 1993, Ellsworth et al 1994, Farges 1994, McLaren et al 1994, Jaeger et al 1997, Colombo and Chrosch 1998a, b, Meldrum et al 1998, Colombo et al 1999, Begg et al 2000, Capitani et al 2000) elucidated some aspects of the mechanism and kinetics of recrystallization of metamict zircon although several issues are still not clear.

Firstly, what happens at an atomic level during high temperature annealing is not known and even the local structure of metamict zircon remains elusive. Based on density and XRD measurements, Weber $(1991,1993)$ reported a two-stage recovery in Pu-doped zircon annealed at high temperatures. The author suggested that the first-stage recovery, appearing near $1323 \mathrm{~K}$, was related to decomposition of damaged zircon and the second-stage recovery was associated with the transformation back to the original $\mathrm{ZrSiO}_{4}$ crystal structure at a higher temperature (the author could not determine exactly when recrystallization to $\mathrm{ZrSiO}_{4}$ structure started due to the uncertainty in the XRD data). An in situ single-crystal neutron diffraction study on partially metamict zircon samples up to $2000 \mathrm{~K}$ by Mursic et al (1992a) showed that for untreated metamict samples the probability density function of the oxygen atoms exhibited minima in directions towards $\mathrm{Zr}$ and Si atoms, but for samples annealed at $1573 \mathrm{~K}$ and $1873 \mathrm{~K}$ the minima disappeared and there was an increased density shift towards the Si atoms. These authors suggested that the observed recrystallization of the damaged zircon could be related to a structural relaxation at high temperatures which was seen in a synthetic sample (Mursic et al 1992b). Farges (1994) reported that XRD data showed a decrease of the cell parameter $a$ from $6.674 \AA$ at $573 \mathrm{~K}$ to $6.610 \AA$ at $873 \mathrm{~K}$ for a damaged zircon and Zr-K EXAFS analysis indicated a progressive (VII) $\mathrm{Zr} \Rightarrow$ (VIII) $\mathrm{Zr}$ transition, associated with a recovery of the crystalline zircon medium-range environment at higher temperatures (approximately between $927 \mathrm{~K}$ and $1273 \mathrm{~K}$ ).

Secondly, although it has been generally agreed that highly metamict zircon tends to decompose into $\mathrm{ZrO}_{2}$ and $\mathrm{SiO}_{2}$ at high temperatures, different polymorphs of $\mathrm{ZrO}_{2}$ have been reported in different studies. In a thermal anneal study using x-rays, Vance and Anderson (1972) reported cubic and tetragonal $\mathrm{ZrO}_{2}$ at $1073 \mathrm{~K}$ and $1373 \mathrm{~K}$, respectively. Farges (1994) reported monoclinic $\mathrm{ZrO}_{2}$ in heavily damaged samples heated to $1373 \mathrm{~K}$. McLaren et al (1994) observed, in heavily damaged zircon with high uranium content, that annealing at $1173 \mathrm{~K}$ produced randomly orientated $\mathrm{ZrO}_{2}$ crystallites of roughly $10 \mathrm{~nm}$ size while annealing at $1523 \mathrm{~K}$ produced baddeleyite crystals (monoclinic $\mathrm{ZrO}_{2}$ ) of $1000 \mathrm{~nm}$ dimensions and an easily identifiable silica glass phase in the regions that were initially optically isotropic. Ellsworth et al (1994) observed crystalline $\mathrm{ZrO}_{2}$ in heavily damaged zircon annealed at $1273 \mathrm{~K}$. Due to its broad x-ray diffraction peaks, these authors could not determine whether it was cubic or 
tetragonal. Ellsworth et al (1994) also pointed out that decomposition of metamict zircon into $\mathrm{ZrO}_{2}$ and $\mathrm{SiO}_{2}$ could be one possible path for recrystallization. An x-ray powder diffraction study at high temperature (Colombo and Chrosch 1998b) reported the appearance of pseudocubic $\mathrm{ZrO}_{2}$. Meldrum et al (1998) observed a decomposition of zircon into tetragonal $\mathrm{ZrO}_{2}$ when irradiating zircon with heavy ions at around $950 \mathrm{~K}$.

Finally, there are some experimental results suggesting that zircon samples with different degrees of damage show different recovery behaviours. A thermoluminescence study by Vaz and Senftle (1971) showed that heating samples with different degrees of $\alpha$-decay damage to $1223 \mathrm{~K}$ for $20 \mathrm{~h}$ in $\mathrm{N}_{2}$ atmosphere resulted in an increase in signals of zircon, but the increase in terms of light output was $\alpha$-dose dependent. Ellsworth et al (1994) reported that the enthalpy (relative to crystalline zircon) of annealing varied sigmoidally as a function of radiation dose and it reached a saturation plateau $\left(-59 \pm 3 \mathrm{~kJ} \mathrm{~mol}^{-1}\right)$ at radiation dose greater than $5 \times 10^{18} \alpha$-events $\mathrm{g}^{-1}$. A recent study using time-differential perturbed angular correlation spectroscopy (Jaeger et al 1997) showed that at some temperatures the degree of recovery was related to the degree of the initial damage of the sample.

We undertook this study to understand the mechanism and kinetics of recrystallization and structural recovery of metamict zircon on annealing. Raman spectroscopy was used because it has a correlation length scale of about a few unit cells and it has been widely used in the study of amorphous and nanometric materials and $\mathrm{ZrO}_{2}$ (Siu et al 1999, Zhang et al 2000). We shall show in later sections that recrystallization in zircon is strongly dose dependent and heavily damaged zircon samples exhibit a more complex recrystallization path than weakly damaged zircon samples. Heating heavily damaged samples to high temperatures can lead to the appearance of tetragonal and monoclinic $\mathrm{ZrO}_{2}$ and unavoidable $\mathrm{SiO}_{2}$ phases. We shall also report experimental data showing the existence of a possible intermediate phase occurring during annealing at temperatures above $800 \mathrm{~K}$.

\section{Experiment}

The samples used in this study were analysed using electron microprobe, $x$-ray and infrared spectroscopy. Seven of them have been previously studied by Murakami et al (1991), Salje et al (1999) and Zhang et al (2000). The lattice parameters of some of the samples were determined by $\mathrm{x}$-ray Guinier powder diffraction with Si as internal standards. Electron microprobe analysis was performed on polished thin sections of zircon samples using a Cameca SX5D electron microprobe with a Link AN10000 energy-dispersive spectrometer. A beam size of $5 \mu \mathrm{m}$ was used with a beam current of $100 \mathrm{nA}$. Tables 1 and 2 list the details. According to x-ray diffraction patterns, unit cell parameters, infrared and Raman spectra, samples Vigene, Moroto, Miass, Green River, UG13, Henderson and 269 are undamaged or slightly damaged (with estimated dose of less than $2 \times 10^{18} \alpha$-events $\mathrm{g}^{-1}$ ); samples Cam26, Cam10 and 4604 have intermediate degrees of damage (between 2 and $3.5 \times 10^{18} \alpha$-events $\mathrm{g}^{-1}$ ); samples Cam27, Ni12 and Z3 are heavily damaged with dose between 5.6 and $7.9 \times 10^{18} \alpha$-events $\mathrm{g}^{-1}$; samples 157 (with dose of $13.1 \times 10^{18} \alpha$-events $\mathrm{g}^{-1}$ ) and $\mathrm{Sd} 4\left(15.9 \times 10^{18} \alpha\right.$-events $\left.\mathrm{g}^{-1}\right)$ are highly metamict. All annealing experiments were carried out in $\mathrm{N}_{2}$ atmosphere in a vertical furnace. Annealed samples were quenched in air.

Raman spectra were recorded at room temperature using a Bruker IFS 66v spectrometer adapted with a Bruker FRA 106 FT-Raman accessory. A silicon-coated calcium fluoride beamsplitter and radiation of $1064 \mathrm{~nm}$ from an Nd:YAG laser were used for the excitation laser which can produce $350 \mathrm{~mW}$ output. A liquid-nitrogen-cooled, high sensitivity Ge detector was used. The spectra were recorded with a laser power of $45-100 \mathrm{~mW}$ and a back scattering geometry. The focused beam was about $200 \mu \mathrm{m}$ in size. For crystalline zircon samples 250-512 scans 
Table 1. Zircon sample descriptions. Dosage is in units of $10^{18} \alpha$-events $\mathrm{g}^{-1}$.

\begin{tabular}{lllllll}
\hline Zircon & Locality & Dose & $a(\AA)$ & $c(\AA)$ & $V\left(\AA^{3}\right)$ & Reference/source \\
\hline Vigene & unknown & ND & 6.6053 & 5.9802 & 260.96 & unknown \\
Moroto & Uganda & ND & 6.6056 & 5.9834 & 261.08 & Peter Leggo \\
Miass & Miass, Urals, Russia & ND & 6.6066 & 5.9813 & 261.06 & NHM \\
Green River & North Carolina, USA & ND & 6.6055 & 5.9827 & 261.04 & NHM \\
UG13 & Uganda & ND & 6.6106 & 5.9943 & 261.95 & Peter Leggo \\
Henderson & North Carolina, USA & ND & 6.6156 & 6.0076 & 262.93 & NHM \\
269 & Sri Lanka & 1.8 & 6.6301 & 6.0266 & 264.91 & Zhang et al $(2000)$ \\
Cam26 & Sri Lanka & 2.9 & ND & Zhang et al $(2000)$ \\
Cam10 & New York, USA & ND & 6.6394 & 6.0549 & 266.91 & CAM \\
4604 & Sri Lanka & 3.5 & 6.68 & 6.07 & 271 & Murakami et al $(1991)$ \\
Cam27 & Sri Lanka & 5.6 & \multicolumn{5}{c}{ ND } & Zhang et al $(2000)$ \\
Ni12 & Sri Lanka & 7.1 & ND & Zhang et al $(2000)$ \\
Z3 & Sri Lanka & 7.6 & unable to determine $a$ and $c$ & HAM \\
157 & Sri Lanka & 13.1 & \multicolumn{5}{c}{ ND } & Zhang et al $(2000)$ \\
Sd4 & Sri Lanka & 15.9 & ND & Zhang et al $(2000)$ \\
\hline
\end{tabular}

ND $=$ not determined.

a Measured by Murakami et al (1991).

CAM = Sedgewick Museum, University of Cambridge, UK; HAM = Mineralogisches Museum, MineralogischPetrographisches, Universität Hamburg, Germany; NHM = Natural History Museum, UK; 269 = BM1920,269; 157 = BM1921,157.

Table 2. Electron microprobe analyses of zircon samples.

\begin{tabular}{lllllllllll}
\hline Sample & $\mathrm{SiO}_{2}$ & $\mathrm{FeO}$ & $\mathrm{ZrO}_{2}$ & $\mathrm{HfO}_{2}$ & $\mathrm{CaO}$ & $\mathrm{Al}_{2} \mathrm{O}_{3}$ & $\mathrm{Y}_{2} \mathrm{O}_{3}$ & $\mathrm{ThO}_{2}$ & $\mathrm{UO}_{2}$ & Total \\
\hline Vigene & 33.39 & - & 66.59 & 0.86 & - & - & 0.03 & 0.01 & 0.01 & 100.89 \\
Moroto & 31.37 & - & 65.64 & 1.28 & 0.01 & 0.01 & 0.01 & 0.01 & 0.02 & 98.34 \\
Miass & 32.01 & - & 65.84 & 1.11 & - & 0.01 & 0.14 & 0.02 & 0.04 & 99.17 \\
UG13 & 30.73 & 0.01 & 65.63 & 1.69 & 0.01 & 0.02 & 0.08 & 0.01 & 0.11 & 98.29 \\
Henderson & 32.81 & 0.04 & 66.12 & 0.92 & - & 0.01 & 0.37 & 0.44 & 0.13 & 100.84 \\
Green River & 32.62 & 0.01 & 65.89 & 0.96 & - & 0.01 & 0.06 & 0.07 & 0.07 & 99.68 \\
Cam26 & 33.36 & 0.01 & 65.26 & 1.28 & 0.01 & - & 0.03 & 0.03 & 0.18 & 100.16 \\
Cam10 & 32.70 & 0.01 & 64.84 & 1.92 & - & - & 0.15 & 0.03 & 0.24 & 99.89 \\
4604 & 32.04 & 0.02 & 66.51 & 1.27 & - & - & 0.10 & 0.08 & 0.32 & 100.34 \\
Cam27 & 33.38 & - & 63.26 & 2.81 & 0.01 & - & 0.22 & 0.05 & 0.36 & 100.09 \\
Ni12 & 32.68 & - & 65.74 & 1.64 & - & 0.01 & 0.02 & 0.14 & 0.39 & 100.62 \\
Z3 & 32.87 & 0.01 & 65.82 & 2.19 & 0.01 & 0.01 & 0.12 & 0.09 & 0.49 & 101.61 \\
157 & 32.48 & 0.01 & 64.85 & 2.36 & 0.05 & - & 0.10 & 0.08 & 0.86 & 100.79 \\
Sd4 & 32.69 & 0.01 & 65.66 & 0.63 & - & 0.01 & 0.01 & 0.12 & 1.02 & 100.15 \\
\hline
\end{tabular}

- Undetectable.

were used and 1000-3000 scans for heavily damaged samples. The resolution of all the spectra was $2 \mathrm{~cm}^{-1}$.

\section{Results}

Nine of the 12 predicted Raman modes $\left(2 \mathrm{~A}_{1 g}+4 \mathrm{~B}_{1 g}+\mathrm{B}_{2 g}+5 \mathrm{E}_{g}\right.$, Dawson et al 1971) were observed in untreated crystalline zircon samples (e.g. samples Vigene, Moroto and Miass), and our results are consistent with previously reported Raman data (Dawson et al 1971, Nicola and Rutt 1974, Syme et al 1977, Nasdala et al 1995, Hoskin and Rodgers 1996, Zhang et al 2000). They are internal modes: $1008 \mathrm{~cm}^{-1}\left(\mathrm{~B}_{1 g}, \mathrm{Si}-\mathrm{O} v_{3}\right.$ stretching), $975 \mathrm{~cm}^{-1}\left(\mathrm{~A}_{1 g}, \mathrm{Si}-\mathrm{O}\right.$ 
$v_{1}$ stretching), $439 \mathrm{~cm}^{-1}\left(\mathrm{~A}_{1 g}, \mathrm{Si}-\mathrm{O} v_{2}\right.$ bending), and $269 \mathrm{~cm}^{-1}\left(\mathrm{~B}_{2 g}, \mathrm{Si}-\mathrm{O} v_{2}\right.$ bending $)$ and external modes: 393, 355, 225, 214 and $202 \mathrm{~cm}^{-1}$ (Syme et al 1977, Hoskin and Rodgers 1996). The other predicted bands are too weak to useful for this study.

\subsection{Effects of annealing temperature}

Raman spectra of zircon samples with different degrees of $\alpha$-decay damage annealed at different temperatures for $1 \mathrm{~h}$ are shown in figure 1 . Thermal annealing reveals different recrystallization processes between partially and heavily damaged samples, i.e. the recrystallization process depends on the cumulative radiation dose. We shall describe the spectral variations due to thermal treatment separately for partially damaged samples and heavily damaged ones.

With increasing annealing temperature, slightly damaged samples (Moroto, Miass, Vigene, Henderson, Green River and UG13), and weakly damaged samples (269 and 4604) show a weak increase of Raman band intensity between $800 \mathrm{~K}$ and $1000 \mathrm{~K}$ (figure 1). Dramatic changes of intensity are observed in the samples annealed between 1000 and $1100 \mathrm{~K}$. An increase of Raman intensity in the region below $300 \mathrm{~cm}^{-1}$ tends to occur between 800 and $900 \mathrm{~K}$ in some partially damaged samples, e.g. 4604 (figure 1). For some crystalline zircon samples, e.g. Miass, Henderson and Green River, thermal annealing between 1600 and $1800 \mathrm{~K}$ causes a decrease of intensity in their Raman signals of crystalline $\mathrm{ZrSiO}_{4}$. This may be due to slight decomposition into monoclinic $\mathrm{ZrO}_{2}$ at these temperatures although no $\mathrm{ZrO}_{2}$ was detected.

For heavily damaged samples (e.g. Ni12, Z3, 157 and Sd4), no significant variations of spectral features were seen between $300 \mathrm{~K}$ and $800 \mathrm{~K}$ (figure 1). In the samples annealed at $900 \mathrm{~K}$, extra spectral features appear near 670,798 and $1175 \mathrm{~cm}^{-1}$. However, these spectral features become weaker in intensity with increasing annealing temperature and could not be traced at temperatures above $1400 \mathrm{~K}$. Apart from these additional signals, tetragonal $\mathrm{ZrO}_{2} \mathrm{was}$ observed in heavily damaged samples (e.g. at $1125 \mathrm{~K}, 1150 \mathrm{~K}$ and $1175 \mathrm{~K}$ for sample Sd4 and at $1200 \mathrm{~K}, 1300 \mathrm{~K}, 1400 \mathrm{~K}$ and $1500 \mathrm{~K}$ for sample 157) while monoclinic $\mathrm{ZrO}_{2}$ was seen above $1600 \mathrm{~K}$ in samples Z3 and Ni12 (figure 1).

The effect of annealing temperature on the structural recovery of damaged zircon can also be clearly seen in the frequency of the $\nu_{3} \mathrm{Si}-\mathrm{O}$ stretching (the band was assigned as $\mathrm{B}_{1 \mathrm{~g}}$ by Syme et al (1977) and Hoskin and Rodgers (1996)) as a function of temperature (figure 2(a)). With increasing annealing temperature the frequency of this mode shows, systematically, a large increase with temperature in the region between $800 \mathrm{~K}$ and $1050 \mathrm{~K}$ and a weaker increase with temperature above $1050 \mathrm{~K}$. Apart from this vibration, the internal Si-O stretching mode near $975 \mathrm{~cm}^{-1}\left(v_{1}, \mathrm{~A}_{1 g}\right)$ and the external mode near $356 \mathrm{~cm}^{-1}\left(\mathrm{E}_{g}\right)$ also show an increase of frequency with temperature (figure 2(b)). In contrast, the frequency of the $\mathrm{Si}-\mathrm{O}$ bending near $438 \mathrm{~cm}^{-1}\left(v_{2}, \mathrm{~A}_{1 g}\right)$ seems almost unaffected by thermal annealing. The other external modes below $300 \mathrm{~cm}^{-1}$ are so weak that we did not attempt to determine the temperature dependence of their frequencies.

\subsection{Effects of annealing time}

In order to understand the effects of annealing time on the recrystallization process in radiationdamaged zircon samples, weakly damaged sample UG13 was annealed for $2 \mathrm{~h}$ between $600 \mathrm{~K}$ and $1700 \mathrm{~K}$ with a temperature interval of $100 \mathrm{~K}$. Raman spectra of the annealed sample show a similar temperature evolution to that of samples (e.g. sample 269) with a similar degree of damage, following annealing for $1 \mathrm{~h}$. 


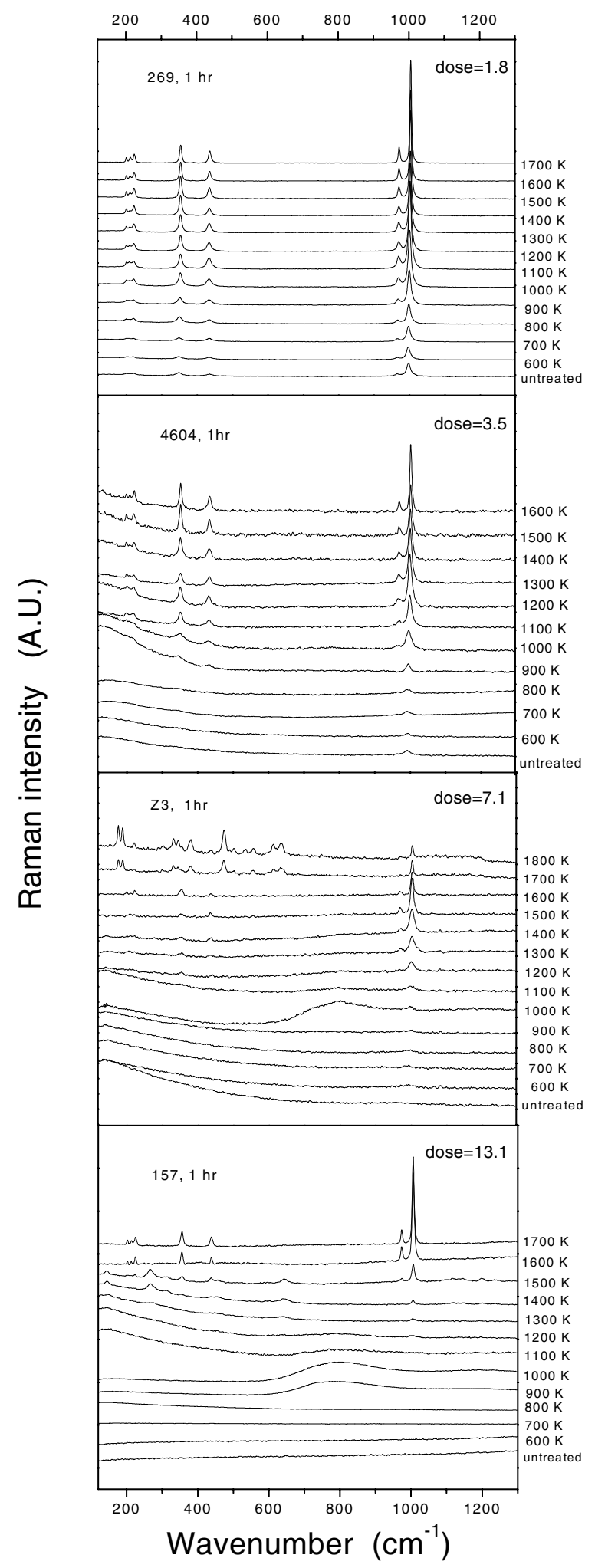

Figure 1. Temperature evolution of Raman spectra of zircon samples with different degrees of radiation damage between 120 and $1300 \mathrm{~cm}^{-1}$. Dosage is in units of $10^{18} \alpha$ events $\mathrm{g}^{-1}$. Samples are annealed for one hour at the designed temperature and then measured before further annealing at a higher temperature. 


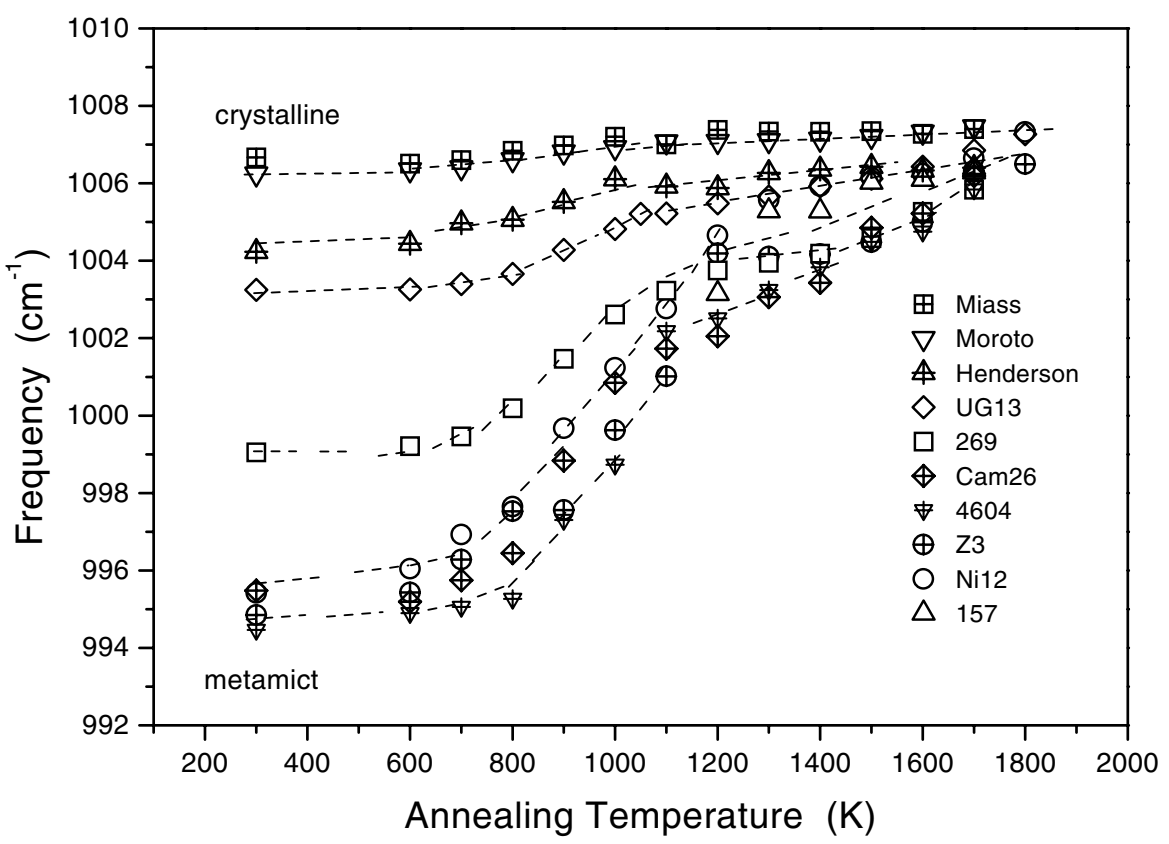

(a)

Figure 2. Phonon frequencies as a function of annealing temperature. (a) $v_{3} \mathrm{Si}-\mathrm{O}$ stretching; (b) external and internal modes for sample 269. All the samples were annealed for $1 \mathrm{~h}$ except $\mathrm{UG} 13$ (2 h) and Cam26 (16 h).

The more significantly damaged samples from zircon Cam26, Cam27 and 157 were annealed for $16 \mathrm{~h}$. These showed similar spectral features to samples annealed for $1 \mathrm{~h}$ except in the temperature region between $900 \mathrm{~K}$ and $1300 \mathrm{~K}$ (figure 1 and figure 3 ). In this temperature region the additional bands near 670,798 and $1175 \mathrm{~cm}^{-1}$ can hardly be detected in Cam26 $\left(\right.$ dose $=2.9 \times 10^{18} \alpha$-events $\left.\mathrm{g}^{-1}\right)$ and Cam27 $\left(\right.$ dose $=5.6 \times 10^{18} \alpha$-events $\left.\mathrm{g}^{-1}\right)$ while they appear as very weak features in a sample from zircon $157\left(\right.$ dose $=13.1 \times 10^{18} \alpha$-events $\left.\mathrm{g}^{-1}\right)$ annealed at $1000 \mathrm{~K}$.

In order to understand why the extra signals are absent or too weak to be detected in longtime annealed samples, samples UG13 and Cam10 were isothermally annealed at $1050 \mathrm{~K}$ up to 22 days and 8 hours (figures 4(a) and 4(b)). We find that the time dependence of the Raman spectra of damaged zircon is also affected by the initial degree of damage. The weakly damaged zircon UG13 $\left(1.6 \times 10^{18} \alpha\right.$-events $\mathrm{g}^{-1}$ which is estimated using the dose-linewidth and dosefrequency dependences reported by Zhang et al (2000) due to the lack of the information on its geological age) shows weak changes in Raman intensity, peak frequency and width (figures 4(a) and 5) with increasing annealing time. However the more significantly damaged zircon Cam10 (estimated dose $=4.2 \times 10^{18} \alpha$-events $\mathrm{g}^{-1}$ ) shows much stronger spectral variations with increasing annealing time. For the case of short annealing time, extra signals located between 500 and $800 \mathrm{~cm}^{-1}$ and near $1175 \mathrm{~cm}^{-1}$ were observed in Cam10 (figure 4(b)) and they exhibit a significant decrease in intensity with increasing annealing time. The Raman spectra of Cam10 in figure 4(b) were normalized against the height of the $v_{3} \mathrm{Si}-\mathrm{O}$ stretching mode to show the relative change of intensity for these extra signals with increasing anneal time. These extra signals become very weak in Cam10 annealed for $16 \mathrm{~h}$ and they can be hardly traced in the spectra of Cam10 annealed for $72 \mathrm{~h}$ and $536 \mathrm{~h}$. These additional signals 


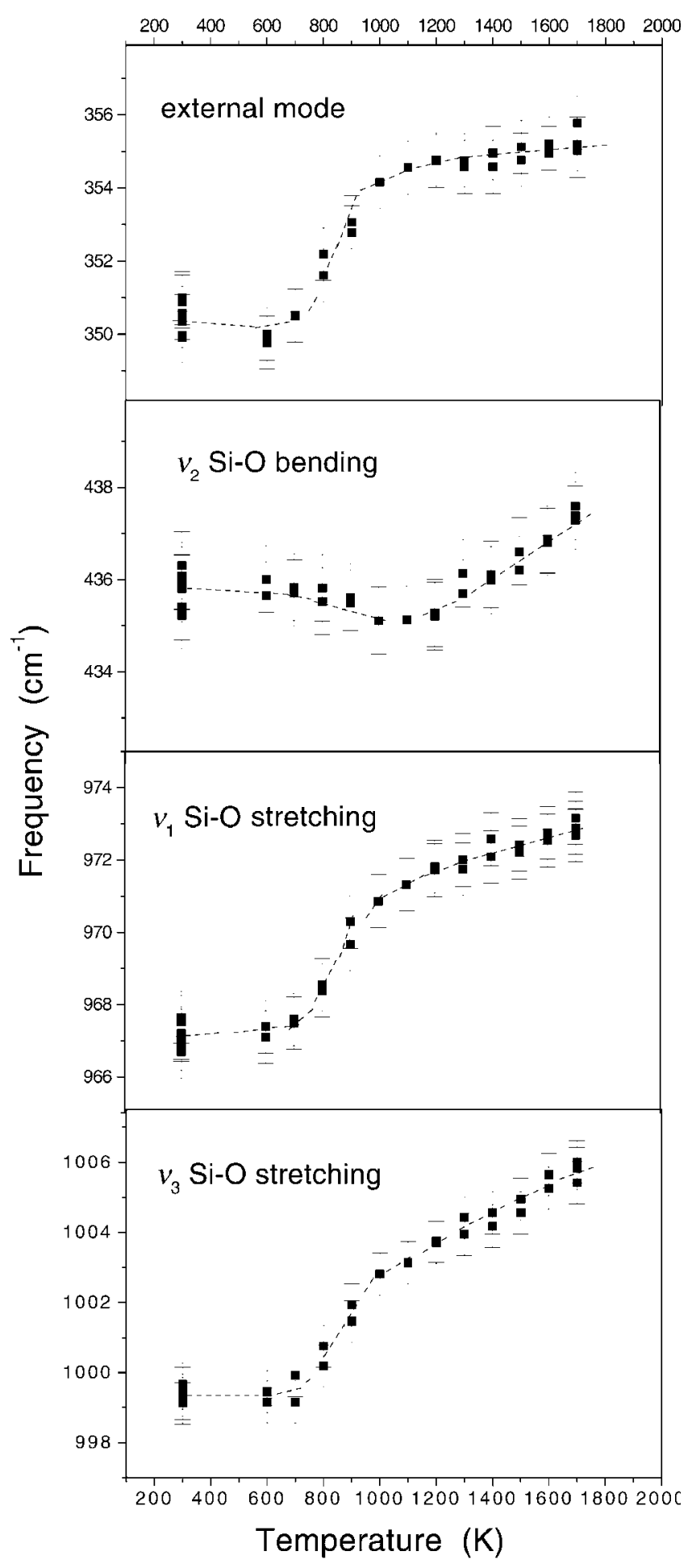

(b)

Figure 2. (Continued) 
Annealing of $\alpha$-decay damage in zircon

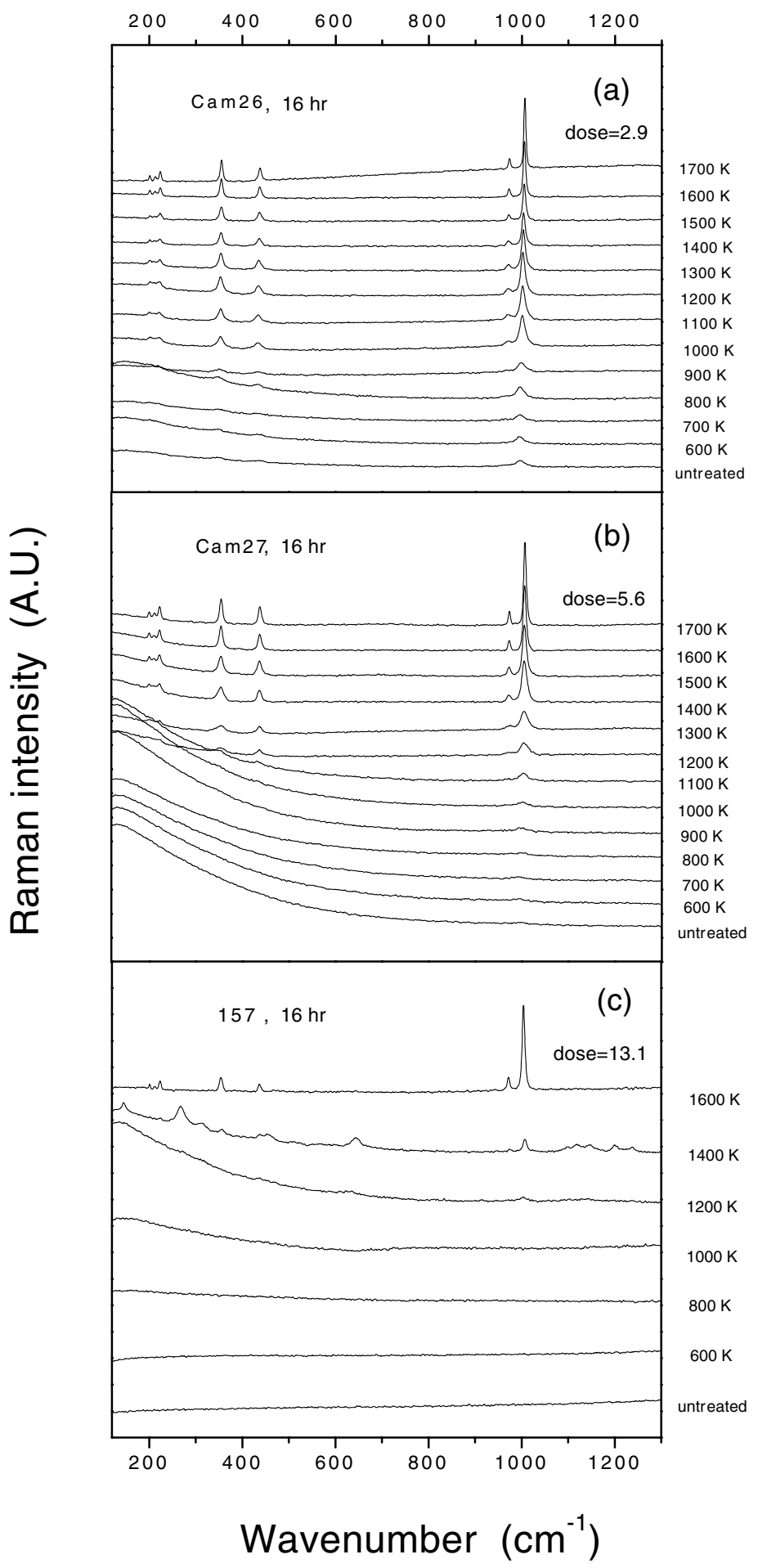

Figure 3. Temperature evolution of Raman spectra between 120 and $1300 \mathrm{~cm}^{-1}$ of zircons annealed for 16h. (a) Cam26; (b) Cam27; (c) 157. Fresh samples were annealed at each temperature. Dosage is in units of $10^{18} \alpha$-events $\mathrm{g}^{-1}$. 


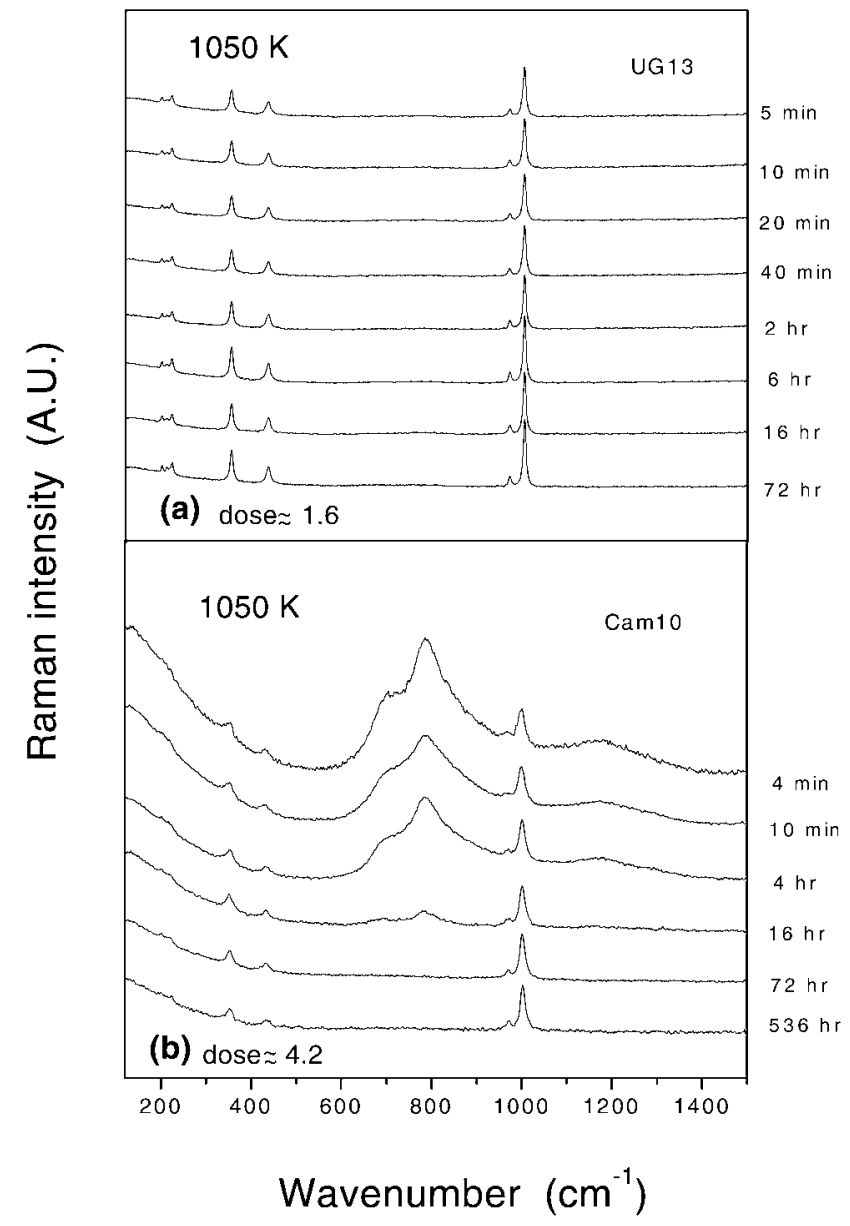

Figure 4. Time evolution of Raman spectra between 120 and $1500 \mathrm{~cm}^{-1}$ (annealing temperature $=$ $1050 \mathrm{~K})$. (a) UG13; (b) Cam10. For the case of (b), the Raman spectra are normalized by the height of the $\mathrm{Si}-\mathrm{O}$ stretching band near $1007 \mathrm{~cm}^{-1}$ to show the detailed spectral changes. Fresh samples were annealed.

could indicate an intermediate phase which starts to appear between $800 \mathrm{~K}$ and $900 \mathrm{~K}$ and it tends to disappear above $1400 \mathrm{~K}$ or during prolonged annealing.

A crystal from sample 157 was annealed at $1100 \mathrm{~K}$ for 21 days. The annealed sample did not show any detectable crystalline $\mathrm{ZrSiO}_{4}$. A crystal of sample 157 annealed at $1400 \mathrm{~K}$ for $16 \mathrm{~h}$ shows sharper Raman lines of crystalline $\mathrm{ZrSiO}_{4}$ than those samples annealed at the same temperature for $1 \mathrm{~h}$ and a higher intensity of $\mathrm{Si}-\mathrm{O}$ stretching $v_{3}$ of $\mathrm{ZrSiO}_{4}$ relative to that of the $643 \mathrm{~cm}^{-1} \mathrm{Zr}-\mathrm{O}$ band of tetragonal $\mathrm{ZrO}_{2}$.

\section{3. $\mathrm{ZrO}_{2}$ and $\mathrm{SiO}_{2}$}

Zirconia has three common polymorphs: the monoclinic, tetragonal and cubic phase (Smith and Newkirk 1965). The different polymorphs of $\mathrm{ZrO}_{2}$ can be distinguished by Raman and infrared spectroscopy. Factor-group analysis predicts the irreducible representations of optical phonons (for zero wave vector) for each polymorph of zirconia $\mathrm{ZrO}_{2}$ (Keramidas and White 


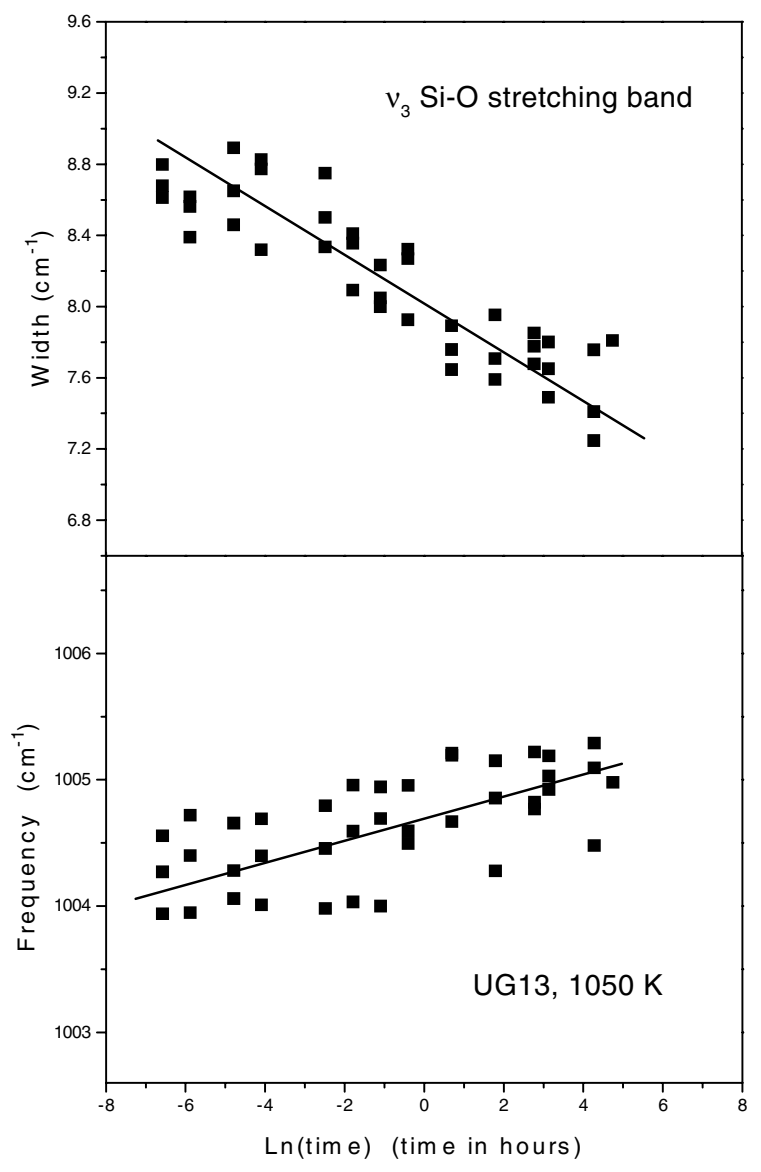

Figure 5. Phonon frequency and width of the $\nu_{3} \mathrm{Si}-\mathrm{O}$ stretching for sample UG13 (isothermally annealed at $1050 \mathrm{~K}$ ) as a function of the natural logarithm of time in hours. The lines are visual guides.

1974, Anastassakis et al 1975). For monoclinic $\mathrm{ZrO}_{2}$ (space group $\mathrm{C}_{2 \mathrm{~h}}^{5} / P 2_{1} / c, Z=4$ ), 18 modes are expected to be Raman active $\left[9 \mathrm{~A}_{g}(\mathrm{R})+9 \mathrm{~B}_{g}(\mathrm{R})+8 \mathrm{~A}_{u}(\mathrm{IR})+7 \mathrm{~B}_{u}(\mathrm{IR})\right]$. In tetragonal $\mathrm{ZrO}_{2}$ with space group $\mathrm{D}_{4 \mathrm{~h}}^{15} / P 4_{2} / n m c(Z=2)$, the predicted representations are $\mathrm{A}_{1 g}(\mathrm{R})+2 \mathrm{~B}_{1 g}(\mathrm{R})+3 \mathrm{E}_{g}(\mathrm{R})+\mathrm{A}_{2 u}(\mathrm{IR})+2 \mathrm{E}_{u}(\mathrm{IR})$ and so six phonon modes are expected to be Raman active. For cubic $\mathrm{ZrO}_{2}$ (space group $\mathrm{O}_{\mathrm{h}}^{5} / F m 3 m, Z=1$ ), the normal modes are $\mathrm{F}_{2 g}(\mathrm{R})+\mathrm{F}_{1 u}(\mathrm{IR})$ and only one Raman mode is expected.

No detectable amounts of either oxide were observed in any of the untreated samples used in this study. With annealing up to $1800 \mathrm{~K}$ slightly damaged zircon samples (Moroto, Miass, Vigene, Henderson and Green River) do not show $\mathrm{ZrO}_{2}$ signals. However, thermal treatment of heavily damaged zircon results in the decomposition of metamict $\mathrm{ZrSiO}_{4}$ into $\mathrm{ZrO}_{2}$ and $\mathrm{SiO}_{2}$. Extra Raman bands at 144, 266, 312, 453 and $645 \mathrm{~cm}^{-1}$ (figures 1, 3 and 6) were recorded in sample 157 (dose $=13.1 \times 10^{18} \alpha$-events $\mathrm{g}^{-1}$ ) annealed at $1200 \mathrm{~K}$. Those signals were also observed in sample $\mathrm{Sd} 4$ annealed at $1125 \mathrm{~K}, 1150 \mathrm{~K}$ and $1175 \mathrm{~K}$. Comparing these signals to published data of $\mathrm{ZrO}_{2}$ (Kim et al 1993, Hirata et al 1994) shows that these signals are characteristic Raman bands of tetragonal $\mathrm{ZrO}_{2}$. Tetragonal $\mathrm{ZrO}_{2}$ could also exist in samples Z3 and Ni12 annealed at $1200 \mathrm{~K}$ as their Raman data between 2000 and $3800 \mathrm{~cm}^{-1}$ 


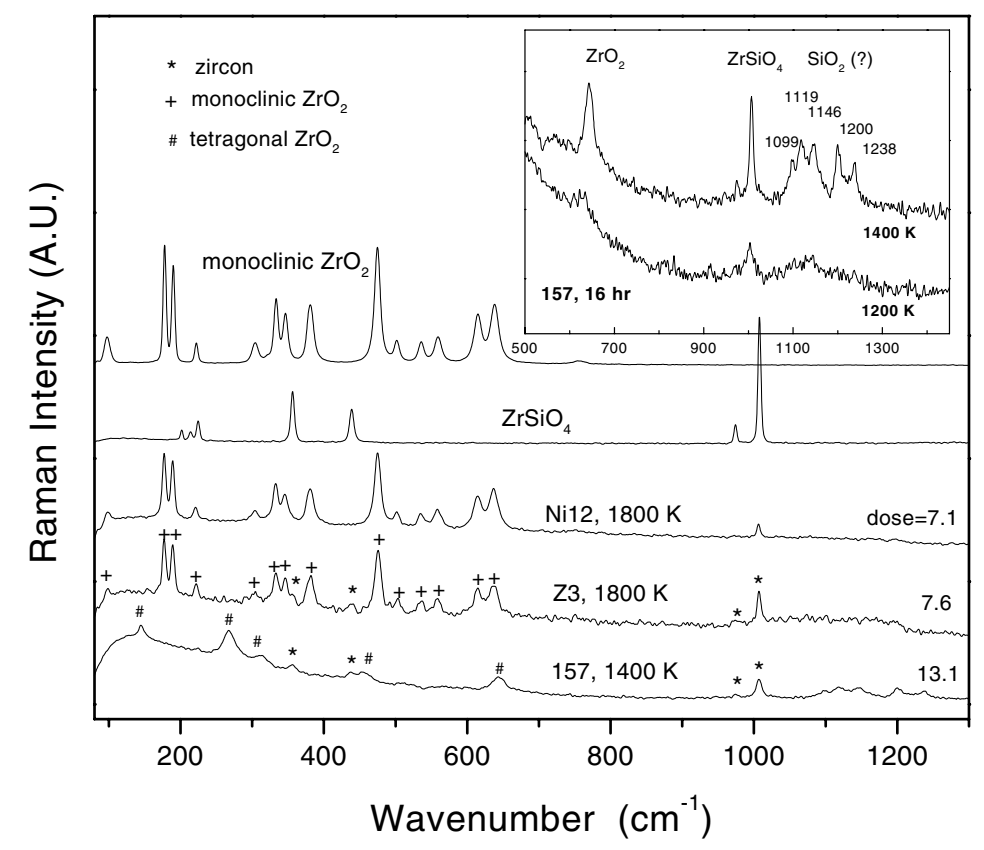

Figure 6. $\mathrm{SiO}_{2}$ and tetragonal and monoclinic $\mathrm{ZrO}_{2}$ were observed in heavily damaged zircons annealed at high temperatures. Dosage is in units of $10^{18} \alpha$-events $\mathrm{g}^{-1}$. The insert shows five resolved Si-O bands are located at 1099, 1119, 1146, 1200 and $1238 \mathrm{~cm}^{-1}$ which are not consistent with $\mathrm{SiO}_{2}$ glass.

show extra signals which are seen in sample 157 annealed at $1200 \mathrm{~K}$. Fourteen other additional Raman bands at 99, 178, 190, 221, 304, 333, 347, 380, 474, 502, 537, 560, 616 and $638 \mathrm{~cm}^{-1}$ together with bands characteristic of zircon are detected in Z3 and Ni12 annealed at above $1600 \mathrm{~K}$ (figures 1 and 6). These additional signals match very well with those obtained from a commercial monoclinic zirconia (Alfa, 99.978\%) (top in figure 6) and the Raman spectrum of monoclinic zirconia reported by Carlone (1992). Their appearance indicates the existence of monoclinic $\mathrm{ZrO}_{2}$ in these annealed samples. The volume of monoclinic $\mathrm{ZrO}_{2}$ in annealed samples may be significantly affected by the quench rate. A crystal of sample Z3 was annealed for $1 \mathrm{~h}$ at $1800 \mathrm{~K}$ and then allowed to cool slowly to room temperature. This sample did not show significant amounts of monoclinic $\mathrm{ZrO}_{2}$. Understanding of the impact of quench rate on the decomposition, however, is beyond the objectives of this study.

We saw no evidence of the presence of cubic $\mathrm{ZrO}_{2}$, which, according to Hirata et al (1994), has only one strong characteristic Raman band $\left(\mathrm{F}_{2 g}\right)$ near $607 \mathrm{~cm}^{-1}$, in any of the annealed samples.

Si-rich material must be accompanied by $\mathrm{ZrO}_{2}$ in order to maintain the original chemical composition of zircon. Such Si-rich phases are correlated with absorption bands between 1000 and $1200 \mathrm{~cm}^{-1}$ where $\mathrm{Si}-\mathrm{O}$ stretching bands from $\mathrm{SiO}_{2}$ glass are commonly located (figure 6). However, it is striking that the Si-rich phase from sample 157 annealed between 1400 and $1500 \mathrm{~K}$ shows five resolved peaks located at 1099, 1119, 1146, 1200 and $1238 \mathrm{~cm}^{-1}$, and these bands are much sharper than those of reported pure $\mathrm{SiO}_{2}$ glass and silicate glasses (Brawer and White 1975, Mysen et al 1980). It is unclear whether the structure of the $\mathrm{SiO}_{2}$ phase due to the decomposition of metamict zircon has different local structures between $1125 \mathrm{~K}$ and $1800 \mathrm{~K}$. 


\section{Discussion}

\subsection{Structural recovery in damaged crystalline domains}

Samples with intermediate degrees of damage contain crystalline and amorphous domains. Thermal annealing of these samples below $900 \mathrm{~K}$ does not produce significant changes in Raman intensities of crystalline zircon (figures 1 and 3). This shows that in this temperature range there is no significant increase in the volume of the crystalline parts implying that the growth of crystalline parts is very slow or absent entirely. This observation is consistent with TEM data from samples Z3 (Capitani et al 2000) as well as the work by McLaren et al (1994).

The increase in phonon frequencies on annealing in this study is consistent with the Raman observations of metamict zircon reported by Nasdala et al (1995) and Zhang et al (2000). These authors observed the converse process, i.e. $\alpha$-decay radiation damage leading to systematic broadening of Raman bands and a significant decrease of Si-O stretching band frequencies reflecting the weakening of the zircon structure and the accumulation of defects. The data from this study also confirm that the observed structural softening in damaged samples by Zhang et al (2000) is due to radiation damage rather than chemical impurities. The remarkable variations in $\mathrm{Si}-\mathrm{O}$ stretching bands during metamictization and thermal annealing are consistent with recent computer simulations of zircon (Williford et al 1998) which suggested displacement energy values of 20.4, 90.4 and $53.1 \mathrm{eV}$ for $\mathrm{Si}, \mathrm{Zr}$ and O, respectively. Our observations also agree with the x-ray work by Farges (1994) who noted a decrease of cell parameter $\boldsymbol{a}$ from 6.674 to $6.610 \AA$ when heating damaged samples from $573 \mathrm{~K}$ to $873 \mathrm{~K}$.

It is striking that the temperature dependences of phonon frequencies of zircon show a kink around $1050 \mathrm{~K}$ (figure 2). The physical implication of this observation is unclear. Based on a single-crystal neutron diffraction measurement at high temperatures, Mursic et al (1992a) proposed that heating a partially damaged zircon to $1250 \mathrm{~K}$ could lead to a structural relaxation involving a sudden expansion of $\mathrm{Si}-\mathrm{O}$ bonds and of $\mathrm{SiO}_{4}$ tetrahedral volume and allow cornersharing $\mathrm{SiO}_{4}$ tetrahedra to rotate. As a result, the strain due to the structural disorder presented in the metamict zircon is released.

The further increase of phonon frequencies and line-sharpening above $1000 \mathrm{~K}$ (figures 1 and 2) indicates that the structure of the recovered crystalline domains is still not perfect. In fact, samples annealed at $1500 \mathrm{~K}$ show Raman bands that are still broader than those of undamaged samples. This suggests that the temperature required for the full recovery of the crystal structure in damaged zircon must be higher than this temperature for a specimen of zircon with intermediate degrees of radiation damage. Vance (1975) reported a complete recovery of the $\mathrm{ZrSiO}_{4}$ infrared spectrum in severely damaged natural zircon after annealing at $1723 \mathrm{~K}$ and Weber (1993) reported that $100 \%$ recovery occurred near $1738 \mathrm{~K}$ for Pu-doped $\mathrm{ZrSiO}_{4}$.

\subsection{Recrystallization and crystal growth}

Thermal annealing reveals different recrystallization processes in partially and highly metamict zircon samples. For partially damaged samples, annealing at $1100 \mathrm{~K}$ for $1 \mathrm{~h}$ results in a significant increase in the intensity of phonon bands of crystalline zircon. It can be understood that the remaining crystalline domains in damaged samples act as seeds for recrystallization. TEM work has shown epitaxial recrystallization in sample Z3 (Capitani et al 2000). The existence and growth of these domains might prevent or restrain amorphous parts from decomposition between $1100 \mathrm{~K}$ and $1200 \mathrm{~K}$. 
Sample 157 annealed at $1100 \mathrm{~K}$ for 21 days did not show signals of crystalline $\mathrm{ZrSiO}_{4}$ and $\mathrm{ZrO}_{2}$, but $\mathrm{ZrSiO}_{4}$ was observed accompanied by tetragonal $\mathrm{ZrO}_{2}$ in sample 157 annealed at $1200 \mathrm{~K}$ for only one hour (figure 1). This observation appears to suggest that the nucleation of crystalline $\mathrm{ZrSiO}_{4}$ in metamict zircon probably occurs between $1100 \mathrm{~K}$ and $1200 \mathrm{~K}$. But a very limited number of damaged crystalline $\mathrm{ZrSiO}_{4}$ domains may still exist in such heavily damaged samples (the radiation doses for 157 and $\mathrm{Sd} 4$ are 13.1 and $15.9 \times 10^{18} \alpha$-events $\mathrm{g}^{-1}$, respectively), and they tend to grow in this temperature region as Salje et al (1999) showed that zircon samples with doses as high as $7.2 \times 10^{18} \alpha$-events $\mathrm{g}^{-1}$ still showed Bragg peaks.

Between $1200 \mathrm{~K}$ and $1400 \mathrm{~K}$, sample 157 does not show any significant increase in the Raman intensity of crystalline $\mathrm{ZrSiO}_{4}$, although a weak signal from the $v_{3} \mathrm{Si}-\mathrm{O}$ stretching vibration was seen at $1200 \mathrm{~K}$. These could be due to the coexistence of $\mathrm{ZrO}_{2}, \mathrm{SiO}_{2}$ and $\mathrm{ZrSiO}_{4}$ in this sample in this temperature region. The growth of crystalline $\mathrm{ZrSiO}_{4}$ is probably restrained by the presence and the growth of the oxides produced by the decomposition. The main recrystallization in sample 157 occurs near $1500 \mathrm{~K}$, and it is evidenced by the dramatic increase of signals of crystalline zircon accompanied by the disappearance of tetragonal $\mathrm{ZrO}_{2}$ (figure 1). This suggests that for this highly metamict sample the main recrystallization (near $1500 \mathrm{~K}$ ) occurs via the reaction of $\mathrm{ZrO}_{2}$ with $\mathrm{SiO}_{2}$ in contrast to partially damaged zircon samples in which the remaining crystalline domains play a dominate role in the epitaxial growth near $1000 \mathrm{~K}$.

We have also noted that it is difficult to determine which recrystallization processes are occurring in some heavily damaged samples (e.g. Cam 27, Ni12 and Z3; with doses of 5.6-7.1 $\times 10^{18} \alpha$-events $\mathrm{g}^{-1}$ ) (see figures 1 and 3). These two different growth mechanisms probably take place simultaneously, but the decomposition into $\mathrm{ZrO}_{2}$ and $\mathrm{SiO}_{2}$ and the appearance of the intermediate phase with characteristic bands near 670, 798 and $1175 \mathrm{~cm}^{-1}$ complicate the analysis of the recrystallization process.

\subsection{Decomposition of $\mathrm{ZrSiO}_{4}$ into $\mathrm{ZrO}_{2}$ and $\mathrm{SiO}_{2}$}

In a comprehensive study using x-ray diffraction, infrared, near infrared and visible spectroscopy, Vance (1975) did not observe $\mathrm{ZrO}_{2}$ in untreated zircon samples and $\mathrm{ZrO}_{2}$ was recorded in only heated samples. Based on x-ray observation of crystalline $\mathrm{ZrO}_{2}$ in two heated samples, Ellsworth et al (1994) suspected the $\mathrm{SiO}_{2}-\mathrm{ZrO}_{2}$ unmixing had occurred in the starting metamict zircon. Zhang et al (2000) reported that $\mathrm{ZrO}_{2}$ and $\mathrm{SiO}_{2}$ are not the principal products of metamictization (but they could not rule out the existence of a small amount of $\mathrm{ZrO}_{2}$ in natural samples due to experimental resolution). The results from our study suggest that $\mathrm{ZrO}_{2}$ and $\mathrm{SiO}_{2}$, as well as an intermediate phase, can occur when damaged samples are heated to high temperatures. Furthermore, our data show that decomposition is more likely to happen in heavily damaged zircon.

Our observation of $\mathrm{ZrO}_{2}$ is consistent with the observations reported by Weber (1991), Ellsworth et al (1994) and McLaren et al (1994). In x-ray diffraction data of zircon samples heated up to $1273 \mathrm{~K}$, Ellsworth et al (1994) did not detect crystalline $\mathrm{ZrO}_{2}$ in eight partially damaged samples with doses ranging from 0.061 up to $6.8 \times 10^{18} \alpha$-events g ${ }^{-1}$, but one sample with dose of $7.2 \times 10^{18} \alpha$-events $\mathrm{g}^{-1}$ showed two phases after annealing, both zircon and $\mathrm{ZrO}_{2}$. In a more damaged sample (with dose of $11.7 \times 10^{18} \alpha$-events $\mathrm{g}^{-1}$ ) heated to $1273 \mathrm{~K}$, only $\mathrm{ZrO}_{2}$ was seen in the diffraction pattern by Ellsworth et al (1994). Our results further support the observations of Ellsworth et al that more heavily damaged samples tend to decompose at high temperatures. The x-ray diffraction peaks were so broad that Ellsworth et al (1994) were unable to determine whether the $\mathrm{ZrO}_{2}$ was tetragonal or cubic. Our results also demonstrate that different $\mathrm{ZrO}_{2}$ polymorphs can be easily determined using Raman spectroscopy. 
It was reported by Meldrum et al (1998) that irradiating synthetic zircon with heavy ions at round $950 \mathrm{~K}$ led to the appearance of tetragonal $\mathrm{ZrO}_{2}$, and the authors explained that the observed decomposition of zircon into $\mathrm{ZrO}_{2}$ and $\mathrm{SiO}_{2}$ was due to heavy-ion irradiation rather than heating. However, our results show that heating alone can produce an unknown intermediate phase around $900 \mathrm{~K}$ while tetragonal $\mathrm{ZrO}_{2}$ appears at a higher temperature (the lowest temperature at which we observed tetragonal $\mathrm{ZrO}_{2}$ is $1125 \mathrm{~K}$ in this experiment). Crystalline $\mathrm{ZrO}_{2}$ has also been observed in annealed natural samples by other workers at temperatures higher than that $(950 \mathrm{~K})$ reported by Meldrum et al (1998) (e.g. $1173 \mathrm{~K}$ by McLaren et al (1994), $1273 \mathrm{~K}$ by Ellsworth et al (1994), at $1373 \mathrm{~K}$ by Vance and Anderson (1972), $1323 \mathrm{~K}$ by Weber (1991), $1173 \mathrm{~K}$ by Colombo and Chrosch (1998b)). Some of these authors might have had problems in the determination of cubic and tetragonal $\mathrm{ZrO}_{2}$ from $\mathrm{x}$-ray diffraction patterns, and the problem of distinguishing between cubic and tetragonal $\mathrm{ZrO}_{2}$ has been discussed by Wittels et al (1962). We may consider several possible causes discussed below which account for the difference of observations between heavy-ion-irradiated zircon and naturally damaged zircon.

Since natural zircon contains appreciable amounts of trace elements, it is expected that the reaction temperature varies due to these impurities. Effects of impurities on amorphization and annealing were noted in ion-beam irradiation studies of natural monazites (with high impurity contents) and synthetic monazite (Meldrum et al 1997b). This may explain the difference in annealing temperature between natural and synthetic zircon samples. The discrepancies may also be due to the nature of the sample forms (bulk versus thin foils) and the type of experiment (high-temperature annealing versus irradiation at high temperature). It is also currently unknown whether there is any possible connection between the phases $\mathrm{ZrO}_{2}$ and $\mathrm{SiO}_{2}$ observed while irradiating zircon with heavy ions near $950 \mathrm{~K}$ by Meldrum et al (1998) and the intermediate phase observed this study which started to appear between $800 \mathrm{~K}$ and $900 \mathrm{~K}$.

This issue may be also related to a fundamental and general question: what is the relationship between the structural characteristic of disordered materials and the various physical processes used to produce the amorphous state? Sales et al (1990) have reported structural differences between a glass state obtained by thermally quenching melts and ionbeam-amorphized states of lead pyrophosphate. In an EXAFS study of the $\mathrm{Zr}$, Th and $\mathrm{U}$ sites in aperiodic/metamict (Ca,Th) $\mathrm{ZrTi}_{2} \mathrm{O}_{7}$ (zirconolite) (Farges et al 1993), it was suggested that there are fundamental structural differences in cation environments between radiationinduced aperiodic (metamict) phases and glasses quenched from melts. In a study of electronirradiation-induced nucleation and growth in $\mathrm{ScPO}_{4}$, Meldrum et al (1997a) noted that samples amorphized using $800 \mathrm{keV} \mathrm{Kr}^{2+}$ ions were somewhat slower to crystallize under electron irradiation than those treated with $1500 \mathrm{keV} \mathrm{Kr}{ }^{+}$ions (requiring $\sim 20 \%$ higher dose). In a study of ion-bombarded and naturally damaged zircon samples, it was reported that several important similarities and differences exist among ion-irradiated specimens and minerals that undergo radiation damage from $\alpha$-decay processes (Meldrum et al 1999). Therefore, it is also unclear whether the above addressed experimental difference is due to the possible structural differences between the ion-irradiation-induced amorphous state and the $\alpha$-decay-radiationinduced metamict state.

The observation of five resolved bands between 1050 and $1250 \mathrm{~cm}^{-1}$ in sample 157 annealed between $1400 \mathrm{~K}$ and $1500 \mathrm{~K}$ was unexpected as TEM observations (McLaren et al 1994) suggested that the Si-rich phase in decomposed samples was silica glass. These well resolved Raman bands observed in this study appear too sharp to be simply taken as a normal $\mathrm{SiO}_{2}$ glass. The apparent implication from our observation is that the local structure of the $\mathrm{Si}$-rich phase in this decomposed zircon is probably different from that of $\mathrm{SiO}_{2}$ glass obtained through quenching melts. 


\subsection{Intermediate phase}

We explain the appearance of additional Raman signals above $800 \mathrm{~K}$ as an indication of a structural modification and the formation of an intermediate phase in the corresponding temperature range. This phase is observed mainly in heavily damaged samples at high temperatures (figures 1 and 4 ) while it could not be detected in untreated zircon. This suggests that this intermediate phase is most likely related to the impact of heating on the damaged parts in metamict zircon. It is unclear whether this phase has the chemical composition of $\mathrm{ZrSiO}_{4}$. However, its characteristic Raman bands near 670,798 and $1175 \mathrm{~cm}^{-1}$ do not match with those of $\mathrm{SiO}_{2}$ glass in terms of the number of Raman bands and their frequencies (Raman bands of $\mathrm{SiO}_{2}$ glass at 430,490,600, 795, 1059 and $1188 \mathrm{~cm}^{-1}$ were observed by Mysen et al 1980) and more clearly the strongest Raman band near $430 \mathrm{~cm}^{-1}$ in $\mathrm{SiO}_{2}$ glass due to $\mathrm{Si}-\mathrm{O}$ bending is absent in this intermediate phase. The lack of the strong characteristic Raman band of cubic $\mathrm{ZrO}_{2}$ near $607 \mathrm{~cm}^{-1}$ (Hirata et al 1994) suggests that these additional signals are unlikely to be due to cubic $\mathrm{ZrO}_{2}$ although tetragonal and monoclinic $\mathrm{ZrO}_{2}$ are observed at higher temperatures. These extra Raman bands seem due to $\mathrm{Si}-\mathrm{O}$ vibrations as their frequencies, especially 788 and $1175 \mathrm{~cm}^{-1}$, are too high for interactions between $\mathrm{Zr}$ and $\mathrm{O}$. If they are $\mathrm{Si}-\mathrm{O}$ bands, the $670 \mathrm{~cm}^{-1}$ band is likely to be due to $\mathrm{Si}-\mathrm{O}$ bending while the 798 and $1175 \mathrm{~cm}^{-1}$ bands probably due to $\mathrm{Si}-\mathrm{O}$ stretching. The appearance of these bands, particularly the $670 \mathrm{~cm}^{-1}$ band, could indicate a different $\mathrm{Si}-\mathrm{O}-\mathrm{Si}$ linkage. At this stage, there is no clear evidence from the Raman data to rule out or to support the conclusion that this phase is due to decomposition of metamict zircon. Holland and Gottfried (1955) observed in their x-ray data a systematic development and disappearance of an extra peak near $2 \theta$ of $35-36.5^{\circ}$ with increasing degree of $\alpha$-decay radiation damage. These authors proposed the formation of an intermediate polycrystalline phase in zircon samples with intermediate dose. It is currently unknown whether there is any possible connection between the intermediate phase proposed by Holland and Gottfried (1955) in unheated samples and the intermediate phase observed this study. Further work by other experimental methods is in progress to understand the nature of the phase observed in our study.

\section{Conclusion}

The experimental results from this Raman study show that the recrystallization and structure recovery process in damaged zircon through thermal annealing are far more complicated than previous observations have indicated, and that partially and very heavily damaged zircons exhibit significantly different recrystallization processes. The main recrystallization process - the epitaxial growth of crystalline zircon-occurs near $1000 \mathrm{~K}$ in partially damaged samples while structural defects in crystalline domains are gradually annealed out at even lower temperatures (starting at $700 \mathrm{~K}$ ). The lattice recovery is indicated by an increase in the phonon frequencies of the $v_{1}$ and $\nu_{3} \mathrm{Si}-\mathrm{O}$ stretching modes and the external band near $357 \mathrm{~cm}^{-1}$ together with a sharpening of those phonon bands with increasing annealing temperature.

Heavily damaged zircon tends to decompose into tetragonal $\mathrm{ZrO}_{2}$ at temperatures around $1125 \mathrm{~K}$ and monoclinic $\mathrm{ZrO}_{2}$ at temperatures above $1600 \mathrm{~K}$. For the highly metamict sample 157 (dose $=13.1 \times 10^{18} \alpha$-events $\mathrm{g}^{-1}$ ), crystalline zircon does not occur until temperatures between $1100 \mathrm{~K}$ and $1200 \mathrm{~K}$ are reached and a dramatic increase in the intensities of the Raman bands of zircon is observed near $1500 \mathrm{~K}$ accompanied by a decrease in the signals of $\mathrm{ZrO}_{2}$ and $\mathrm{SiO}_{2}$. This indicates that the $\mathrm{ZrSiO}_{4}$ crystal growth in this metamict sample is associated with the reaction of $\mathrm{ZrO}_{2}$ with $\mathrm{SiO}_{2}$. 
Extra Raman signals near 670, 798 and $1175 \mathrm{~cm}^{-1}$ have been recorded, for the first time, by Raman spectroscopy in heavily damaged samples. These bands start to appear at around $800 \mathrm{~K}$ and becomes undetectable in samples annealed above $1400 \mathrm{~K}$. This observation probably suggests the existence of an intermediate phase in this temperature range.

Increasing annealing time does not significantly affect the recrystallization mechanisms and the decomposition process except that it causes changes in the real volumes of the observed different phases. Prolonged isothermal annealing at $1050 \mathrm{~K}$ results in a dramatic decrease in the signals due to the intermediate phase and eventually they become undetectable in a sample annealed for 28 days and 8 hours.

\section{Acknowledgments}

The authors thank S J B Reed for assistance with the electron microprobe analysis, A GraemeBarber for assistance with the X-ray diffraction analysis and P Leggo for providing samples UG13 and Moroto used in this study. Financial support from EU network ERB-FMRX-CT970108 is gratefully acknowledged.

\section{References}

Anastassakis E, Papanicolaou B and Asher I M 1975 J. Phys. Chem. Solids 36667

Anderson E B, Burakov B E and Vasiliev V G 1993 Proc. Safe Waste '93 vol 2 p 29

Begg B D, Hess N J, Weber W J, Conradson S D, Schweiger M J and Ewing R C $2000 \mathrm{~J}$. Nucl. Mater. at press

Brawer S A and White W B 1975 J. Chem. Phys. 632421

Burakov B E 1993 Proc. Safe Waste '93 vol 2 p 19

Capitani G C, Leroux H, Doukhan J C, Ríos S, Zhang M and Salje E K H 2000 Phys. Chem. Mineral at press

Carlone C 1992 Phys. Rev. B 452079

Colombo M and Chrosch J 1998a Radiat. Phys. Chem. 53555

_1998b Radiat. Phys. Chem. 53563

Colombo M, Chrosch J, Biagini R and Memmi I 1999 Neues Jahrbuch Mineral.-Monatshefte 113

Dawson P, Hargreave M M and Wilkinson G F 1971 J. Phys. C: Solid State Phys. 4240

Ellsworth S, Navrotsky A and Ewing R C 1994 Phys. Chem. Mineral. 21140

Ewing R C 1994 Nucl. Instrum. Methods B 9122

1999 Proc. Natl Acad. Sci. 963432

Ewing R C, Lutze W and Weber W J 1995 J. Mater. Res. 10243

Farges F 1994 Phys. Chem. Mineral. 20504

Farges F, Ewing R C and Brown G E Jr 1993 J. Mater. Res. 81983

Hazen R M and Finger L W 1979 Am. Mineral. 64157

Hirata T, Asari E and Kitajima M 1994 J. Solid State Chem. 110201

Holland H D and Gottfried D 1955 Acta Crystallogr. 8291

Hoskin P W O and Rodgers K A 1996 Eur. J. Solid State Inorg. Chem. 331111

Jaeger H, AbuRaddad L and Wick D J 1997 Appl. Radiat. Isot. 481083

Keramidas V G and White W B 1974 J. Am. Ceram. Soc. 5722

Kim D J, Jung H J and Yang I S 1993 J. Am. Ceram. Soc. 762106

McLaren A C, Fitz J D and Williams I S 1994 Geochim. Cosmochim. Acta 58993

Meldrum A, Boatner L A and Ewing R C 1997a J. Mater. Res. 121816

-1997b Phys. Rev. B 5613805

Meldrum A, Boatner L A, Zinkle S J, Wang S X, Wang L M and Ewing R C 1999 Can. Mineral. 37207

Meldrum A, Zinkle S J, Boatner L A and Ewing R C 1998 Nature 39556

Murakami T, Chakoumakos B C, Ewing R C, Lumpkin G R and Weber W J 1991 Am. Mineral. 761510

Mursic Z, Vogt T, Boysen H and Frey F 1992a J. Appl. Crystallogr. 25519

Mursic Z, Vogt T and Frey F 1992b Acta Crystallogr. B 48584

Mysen B O, Virgo D and Scarfe C M 1980 Am. Mineral. 65690

Nasdala L, Irmer G and Wolf D 1995 Eur. J. Mineral. 7471

Nicola H H and Rutt H N 1974 J. Phys. C: Solid State Phys. 71381 
Sales B C, Ramey J O, McCallum J C and Boatner L A 1990 J. Non-Cryst. Solids 126179

Salje E K H, Chrosch J and Ewing R C 1999 Am. Mineral. 841107

Siu G G, Stokes M J and Liu Y 1999 Phys. Rev. B 593173

Smith D K and Newkirk H K 1965 Acta Crystallogr. 18982

Stott V H and Hilliard A 1946 Mineral. Mag. 27198

Syme R W G, Lockwood D J and Kerr H J 1977 J. Phys. C: Solid State Phys. 101335

Vance E R 1975 Radiat. Eff. 241

Vance E R and Anderson B W 1972 Mineral. Mag. 38605

Vaz J E and Senftle F E 1971 J. Geophys. Res. 762038

Weber W J 1991 Radiat. Eff. Defects Solids 115341

-1993 J. Am. Ceram. Soc. 761729

Weber W J, Ewing R C and Lutze W 1996 Mater. Res. Soc. Symp. Proc. vol 412 (Pittsburgh, PA: National Research Society) p 25

Williford R E, Devanathan R and Weber W J 1998 Nucl. Instrum. Methods B 14194

Wittels M C, Steigler J O and Sherrill F A 1962 J. Nucl. Energy A/B 16237

Zhang M, Salje E K H, Farnan I, Graeme-Barber A, Daniel P, Ewing R C, Clark A M and Leroux H 2000 J. Phys.: Condens. Matter 121915 